\title{
Problema de Escoamento Não Saturado em Meios Porosos Rígidos
}

\author{
Daniel Moutinho de Souza Riedson Baptista \\ Departamento de Matemática Aplicada, CEUNES, UFES, \\ 29932-540, São Mateus, ES \\ E-mail: danielmoutinho11@gmail.com,riedsonb@ceunes.ufes.br
}

\section{RESUMO}

Este trabalho de Iniciação Científica apresenta uma formulação numérica para o problema de escoamento não saturado em meios porosos rígidos. O escoamento é governado pela lei de conservação de massa para fase ar e água e pela lei de Darcy [1], considerando a incompressibilidade do escoamento que ocupa todo o meio poroso rígido, homogêneo e isotrópico chegamos a equação de Richards. A Equação de Richards é uma equação diferencial parcial não linear que governa o processo de escoamento não saturados em meios porosos rígidos. Tendo em vista sua não linearidade soluções analíticas e numéricas tonam-se difíceis. Porém este problema pode ser contornado por algumas aproximações.

Em nosso estudo trabalhamos com fluido bifásico água-ar, porém em geologias rasas a fase ar pode ser aproximada pela pressão atmosférica constante. Desta forma o problema de escoamento não saturado se resume apenas a conservação de massa para a fase água como mostrado na equação a seguir:

$$
\nabla \cdot\left(K \cdot \nabla p_{a}\right)=\frac{\partial \theta}{\partial t}
$$

onde, $K$ é o tensor de condutividade hidráulica, $\theta$ é o teor de umidade, $t$ é o tempo e $p_{a}$ é a fonte de pressão. Para fluidos em meios porosos este potencial pode ser dado por $p_{a}=\psi+z$, onde $\psi$ é o potencial piezométrico e $z$ é a coordenada de elevação (direção vertical). Para um meio homogêneo e isotrópico, o tensor de condutividade hidráulico $K$ é dado pelo produto do escalar $k$ pela matriz identidade. Consideramos assim $k=k_{r} k_{s}$, onde $k_{r}$ é condutividade hidráulica relativa para o solo não saturado e $k_{s}$ é a condutividade hidráulica do solo saturado. Assim obtemos a seguinte forma para a equação de Richards:

$$
\nabla \cdot\left(k_{r} \nabla \psi\right)+\frac{\partial k_{r}}{\partial z}=\frac{1}{k_{s}} \frac{\partial \theta}{\partial t}
$$

Van Genuchten [2], [3], tem aproximações realísticas para condutividade hidráulica e saturação efetiva, porém uma expressão mais simples, porém muito importante para obtenção da solução analítica para a equação (2), é a formulação de Gardner [2], [3] descrita abaixo:

$$
k_{r}=S e=e^{\alpha \psi}
$$

onde, $\alpha$ é um parâmetro com base no tipo do solo. Usamos a equação (3) para a condutividade hidráulica relativa, sendo o teor de umidade dado por:

$$
\theta=\theta_{d}+\left(\theta_{s}-\theta_{d}\right) S_{e}
$$

onde, $\theta_{d}$ é o teor de umidade quando o solo está drenado e $\theta_{s}$ o teor de umidade quando o solo está saturado. Utilizando separação de variáveis e série de Fourrier obtemos a seguinte solução para a equação (2):

$$
\psi=\frac{1}{\alpha} \ln (\bar{\psi}+\epsilon)
$$


onde

$$
\bar{\psi}=\left(1-e^{\alpha \psi_{d}}\right) e^{\frac{\alpha}{2}(L-z)}\left[\frac{\operatorname{senh}\left(\frac{\alpha}{2} z\right)}{\operatorname{senh}\left(\frac{\alpha}{2} L\right)}+\frac{2}{L c} e^{\frac{\alpha}{2}(L-z)} \sum_{k=1}^{\infty}(-1)^{k} \frac{\lambda_{k}}{\mu_{k}} \operatorname{sen} \lambda_{k} z e^{-\mu_{k} t}\right],
$$

com

$$
c=\frac{\alpha\left(\theta_{s}-\theta_{d}\right)}{k_{s}}, \quad \mu_{k}=\frac{\alpha^{2}}{4}+\lambda_{k}^{2}, \quad \lambda_{k}=\frac{\pi}{L} k
$$

sendo $\psi_{d}$ a pressão quando o solo está drenado, $k=0,1,2, \cdots$ e $t$ a evolução temporal.

A seguir apresenta-se um experimento utilizando a solução obtida.
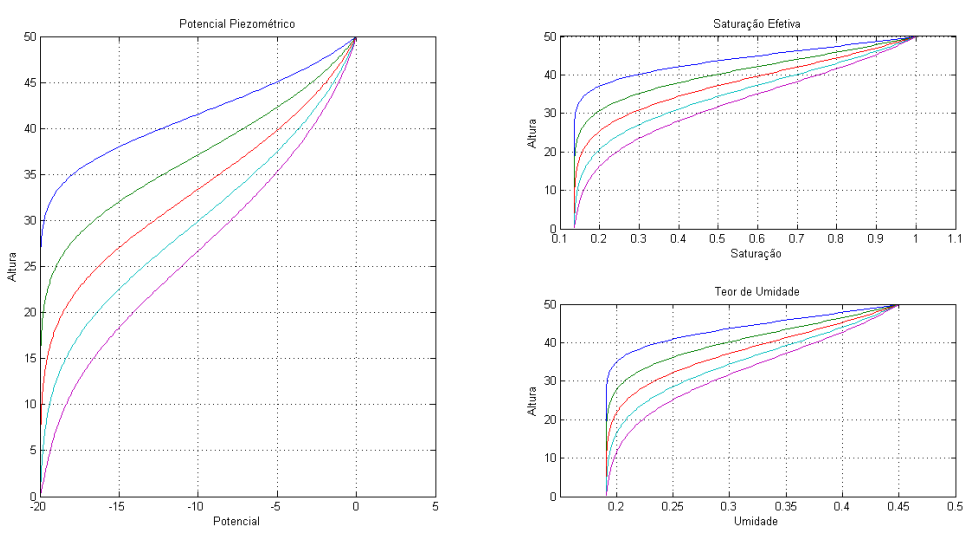

Figura 1: $L=50 m ; k_{s}=0,1 \mathrm{~m} /$ dia $; h_{d}=-20 m ; \theta_{d}=0,15 ; \theta_{s}=0,45 ; \alpha=0,1 m^{-1}, T_{f}=$ 30 dias com $\Delta t=6$ dias

Como trabalhos a serem realizados futuramente, destacam-se: Resolução numérica usando Método de Elementos Finitos para o espaço e Diferenças Finitas para o tempo e imposição de condutividade hidráulica e saturação mais realísticos.

Palavras-chave: Equação de Richards, Meios Porosos, Solução Analítica

\section{Referências}

[1] A.J. Rosa, R. S. Carvalho, J. A. D. Xavier. "Engenharia de Reservatório de Petróleo", Interciência, Rio de Janeiro, RJ, 2006.

[2] M.L.P. Pizarro, "Simulação de fluxo de água e transporte de solutos na zona não saturada do solo pelo método de elementos finitos adaptativo", Tese de Doutorado, Escola de Engenharia de São Carlos-USP, 2009.

[3] M. Mannich, "Desenvolvimento de soluções analíticas e numéricas da equação de Richards", Dissertação de Mestrado, PPGERHA-UFPR, 2008. 